This item was submitted to Loughborough's Research Repository by the author.

Items in Figshare are protected by copyright, with all rights reserved, unless otherwise indicated.

\title{
Design data for footwear: sweating distribution on the human foot
}

PLEASE CITE THE PUBLISHED VERSION

http://dx.doi.org/10.1108/09556221311292200

\section{PUBLISHER}

(c) Emerald Group Publishing Limited

\section{VERSION}

AM (Accepted Manuscript)

\section{LICENCE}

CC BY-NC-ND 4.0

\section{REPOSITORY RECORD}

Smith, Caroline J., Christiano A. Machado-Moreira, Gijs Plant, S.G. Hodder, George Havenith, and Nigel A.S. Taylor. 2019. "Design Data for Footwear: Sweating Distribution on the Human Foot". figshare. https://hdl.handle.net/2134/11935. 
This item was submitted to Loughborough's Institutional Repository (https://dspace.lboro.ac.uk/) by the author and is made available under the following Creative Commons Licence conditions.

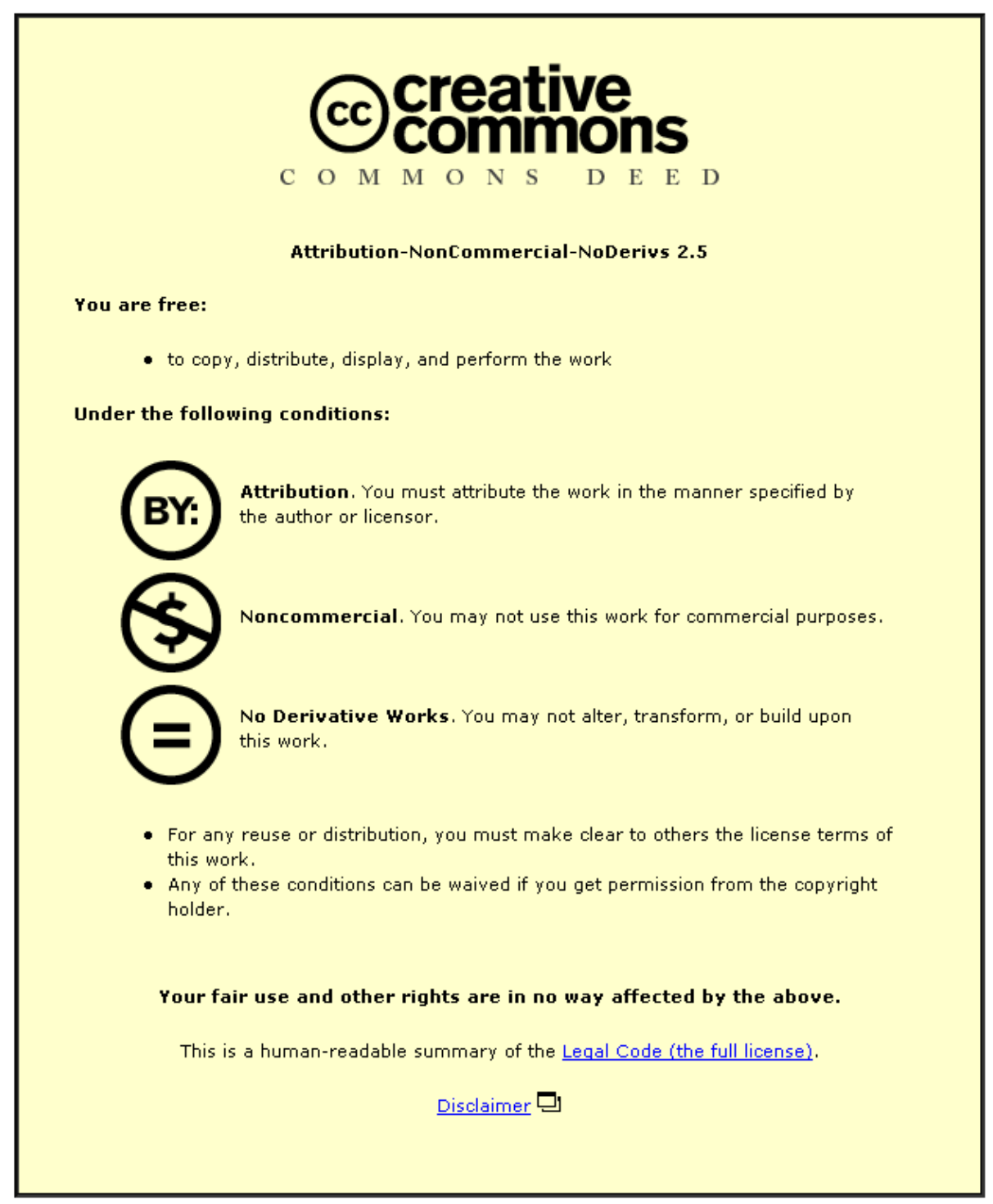

For the full text of this licence, please go to: http://creativecommons.org/licenses/by-nc-nd/2.5/ 


\section{Design Data for Footwear - Sweating Distribution on the Human Foot}

Caroline J. Smith ${ }^{1}$, Christiano A. Machado-Moreira ${ }^{2}$, Gijs Plant ${ }^{2}$, Simon Hodder ${ }^{1}$, George Havenith ${ }^{1}$ and Nigel A.S. Taylor ${ }^{2}$

Prepared for: Int. J. Clothing Science and Technology TYPE: Research Paper

\section{Affiliations:}

${ }^{1}$ Environmental Ergonomics Research Centre, Loughborough University Design School, Loughborough, LE11 3TU, United Kingdom.

${ }^{2}$ Centre for Human and Applied Physiology, School of Health Sciences, University of Wollongong, Wollongong, NSW 2522, Australia.

\section{Corresponding author:}

George Havenith, Ph.D.

Environmental Ergonomics Research Centre, Loughborough University Design School, Loughborough University, Loughborough, LE11 3TU, United Kingdom.

Phone: +44 (0)1509 223031

Fax: +44 (0)1509 223940

Email: G.Havenith@lboro.ac.uk 


\section{Brief details of the authors:}

Caroline Smith, PhD, studied Biology at Loughborough University and achieved her PhD in 2009, with Professor Havenith as supervisor. The theme of her PhD was mapping of human sweat rate distribution over the body. She currently works as a post-doc at Pennsylvania State University.

Christiano Machado-Moreira MSc has recently completed currently his PhD under Associate Professor Nigel Taylor (University of Wollongong). His doctoral studies centred upon the neural control of eccrine sweating during thermal and psychological stimulation.

Gijs Plant BSc and Simon Hodder PhD supported the research in both labs.

Professor George Havenith is director of the Environmental Ergonomics Research Centre at Loughborough University. His research area is heat transfer in clothing and physiological responses to thermal stress.

Associate Professor Nigel Taylor is the current Director of the Centre for Human and Applied Physiology at the Wollongong University (Australia). He is an Environmental Physiologist with a special interest in the neural control of human eccrine sweating.

\section{Acknowledgements}

2 This research was partially funded by the Adidas Innovation Team and the

3 Loughborough University Design School. Christiano Machado-Moreira was

4 supported by a Doctoral scholarship from Coordenação de Aperfeiçoamento de

5 Pessoal de Nível Superior - CAPES (Ministry of Education, Brazil). 


\section{Design Data for Footwear - Sweating Distribution on the Human Foot}

\section{Abstract}

Purpose: To provide footwear designers, manikin builders and thermo-physiological modellers with sweat distribution information for the human foot. Methodology: Independent research from two laboratories, using different techniques, is brought together to describe sweat production of the foot. Thirty-two individuals were studied. One laboratory used running at two intensities in males and females, and measured sweat with absorbents placed inside the shoe. The other used ventilated sweat capsules on a passive, nude foot, with sweating evaluated during passive heating and incremental exercise to fatigue. Findings: Results from both laboratories are in agreement. Males secreted more than twice the volume of sweat produced by the females $(P<0.01)$ at the same relative work rate. Both genders demonstrated a nonuniform sweat distribution, though this was less variable in females. Highest local sweat rates were observed from the medial ankles $(P<0.01)$. The dorsal foot sweated substantially more than the plantar (sole) areas $(P<0.01)$. Sweating on the plantar side of the foot was uniform. Wearing shoes limited the increase in sweat production with increasing load, while the sweat rate of uncovered feet kept increasing with work and thermal load. Practical implications: The observed variation in sweat rate across the foot shows that footwear design should follow the body mapping principle. Fabrics and materials with different properties can be used to improve comfort if applied to different foot surfaces. These data also demonstrate that foot models, whether physical (manikins) or mathematical, need to incorporate the observed variation across the foot to provide realistic simulation/testing of footwear. Originality: This paper provides comprehensive and novel data to be used in footwear design.

Keywords: clothing, evaporation, feet, footwear, heat, shoes, socks, sweating 


\section{1. Introduction}

2 Foot sweat production is affected by both physiological and psychological factors.

3 Sweat glands from the plantar surfaces (sole) of the feet are stimulated during

4 psychological stress (Kuno, 1956; Machado-Moreira and Taylor, 2011a and 2011b)

5 and, to a lesser extent, by changes in body heat storage (Hertzman et al., 1952;

6 Wurster et al., 1969; Allen et al., 1978). It is generally considered that the dorsal

7 (upper) foot surface responds more to thermal stimuli than to psychogenic

8 influences. Until recently (Taylor et al., 2006; Fogarty et al., 2009; Smith and

9 Havenith, 2011; Taylor and Machado-Moreira, 2011), little was known about the

10 distribution of sweating among the foot surfaces. However, for advances to occur in

11 footwear design (socks and shoes) and in the tools used in that research, such as

12 thermal manikins, 'sweating feet' designed to quantify the vapour resistance of

13 textiles, clothing and footwear, or for development of mathematical models of foot

14 heat loss (Covill et al., 2011; Kuklane et al., 2000b; Mekjavic et al., 2005), more detailed information is required than is currently available (Havenith, 2002; Havenith et al. $2008^{b}$ ). Moreover, clothing and fabric manufacturers have sought to develop garments that better support heat dissipation by taking advantage of regional variations in physiological heat dissipation (body mapping). Such an approach may be possible in footwear development when more information on foot sweating is available. For example, manufacturers may incorporate fibres having superior moisture removal qualities into specific locations of the sock, such that socks more closely match physiological demands.

Accordingly, two laboratories have been independently and simultaneously mapping the regional distribution of human sweat secretion using different techniques. One group was responding to the interests of clothing manufacturers (Loughborough University, United Kingdom), whilst the other was driven by questions related to the development of sweating, thermal manikins (University of Wollongong, Australia). Being aware of each other's work, and also of the broad applications of the resulting data, it was decided that a collaborative report should be written, in which both groups would present their latest data for foot sweating, thus helping readers to 
1 obtain a more complete appreciation of intra-segmental variations in sweating from

2 one source.

4 One group had previously documented the temporal and spatial characteristics of sweating for five surfaces of the foot (Taylor et al., 2006). However, for the current report, a new experiment (using different participants) was performed, in which the methods were refined, measuring eleven foot sites and increasing the sample size from six to ten participants. Within this laboratory, local sweat rates are measured using ventilated sweat capsules. For this technique, air of a known water vapour pressure is passed over the target skin surface, covered by a sealed capsule, at a pre-determined flow. This is regulated to ensure complete evaporation, thereby increasing the water vapour pressure of the effluent, which is measured downstream, permitting derivation of the local sweat rate (Taylor et al., 1997). Thus, the skin is maintained in a constantly dry state (with possibly a slightly lower skin temperature than normal due to more efficient evaporation), causing this condition to differ from that which is usually seen. Normally, when sweat rates are sufficiently elevated, some sweat remains unevaporated, and over a long period ( $>1$ hour) this can reduce the volume of discharged sweat due to increased cutaneous hydration (hidromeiosis: Collins and Weiner, 1962). Therefore, sweat rates recorded using ventilated capsules represent ideal secretion rates, and these are typically higher than might otherwise be obtained. Nevertheless, this technique is very sensitive, and can even quantify insensible (transpirational) water losses, offering considerable temporal and spatial precision, whilst providing superior dynamic sensitivity. This method is ideal for investigating differences in intra-segmental sweat secretion.

The second group has previously communicated observations on the sweating foot during loaded, uphill walking (Fogarty et al., 2009) and on whole-body sweat distribution in males (Smith and Havenith, 2011). The present data expand these, using slightly modified techniques and a much larger sample of athletes (increased from nine to 22), including females, running at 50 and $70 \%$ of peak aerobic power (8 to $12 \mathrm{~km} \cdot \mathrm{h}^{-1}$ ), representing training level running efforts. This laboratory chose to use 
1 absorbent patches attached to the target skin surfaces. These are replaced at fixed

2 intervals, with mass changes indicating local sweat rates. This technique is ideally

3 suited for a wide variety of applications for which ventilated capsules may become

4 impractical, for example inside a shoe (Smith et al., 2007; Havenith et al., 2008 ${ }^{\mathrm{a}}$ ).

5 With this technique, where the skin is covered with absorbent patches for

6 approximately 5 minutes of every half hour, local sweat production may be reduced

7 as the microclimate water vapour pressure under the patch increases in this period

8 (no liquid sweat should remain on the skin as less than $5 \%$ of the patches'

9 absorptive capacity is used). Such a hidromeiotic effect is, however, only seen after

10 long periods of wet skin, but in general one may expect this method to under- rather

11 than over-estimate (as with the capsule method) actual sweat rates, especially in

12 normally uncovered skin. For application to the foot, where sweat evaporation in the

13 shoe is limited in most cases, the conditions in this method may be closer to the real

14 life situation. Nonetheless, this technique is also very good for investigating differences in intra-segmental sweat secretion, and data will reflect secretion rates from larger surface areas under clothing than is the case with capsule measurement techniques, which typically cover an area $<15 \mathrm{~cm}^{2}$.

By bringing together data obtained with both methods and from two independent sources, the reader is provided with the most current and advanced dataset on foot sweat distribution. One could reasonably assume that actual sweat rates in the field may fall within the zones defined by these two datasets, obtained from a total population sample of thirty-two individuals (males and females) during passive heating, running, and cycling to volitional fatigue. These data should help designers of socks and shoes to select the optimal materials for different parts of the foot and, for example, to target the wettest areas by providing extra ventilation for improving heat dissipation and comfort. 


\section{2. Methods}

2 2.1. Sweat-patch study:

3 2.1.1. Participants

4 Twenty-two runners (nine males and 13 females: 21.6 y (SD 3.0), $64.8 \mathrm{~kg}$ (SD 10.0),

$5170.8 \mathrm{~cm}(\mathrm{SD} 9.0)$ ) performed $60 \mathrm{~min}$ of treadmill running, with the first $35 \mathrm{~min}$ at a

6 low intensity (target 50\% of maximal aerobic power; heart rate $125-135$ beats. min $^{-1}$ ),

7 followed by 25 min at a higher intensity (target $70 \%$ maximal power, heart rate

$8 \quad 150-160$ beats $\left.\mathrm{min}^{-1}\right)$. Trials were conducted in a climate-controlled room $\left(25^{\circ} \mathrm{C}\right.$ and

$945 \%$ relative humidity). All procedures were approved by the Loughborough

10 University Ethics Committee, with participants being screened for normal health

11 status before providing written, informed consent.

13 2.1.2. Preliminary methods:

14 Participants first attended the laboratory for a sub-maximal exercise test and anthropometric measurements. The latter were used to calculate sweat pad dimensions for each participant, with two sets of five pads for each foot (Figure 1A) cut from absorbent material (Technical Absorbents Ltd., Grimsby, U.K.). For the sixth site on each foot (dorsal surface), the cotton sock itself was used as the absorbent. These pads were weighed inside individual, pre-weighed, air-tight bags (Sartorius 1213MP, Sartorius AG, Gottingen, Germany; resolution $0.01 \mathrm{~g}$ ). The exercise test was used to determine the experimental running speeds that would elicit the two target work rates.

\subsubsection{Experimental methods:}

29 Participants were advised to consume water $\left(20 \mathrm{~mL} . \mathrm{kg}^{-1}\right)$ during the $2 \mathrm{~h}$ prior to testing to maintain a euhydrated state. They were also advised against the use of alcohol during the $24 \mathrm{~h}$ before testing, and the consumption of either food or caffeine 
1 within $2 \mathrm{~h}$ of experimentation. Prior to each experimental run, participants were weighed within minimal clothing, with weighing repeated immediately after each trial. Water consumption was ad libitum during testing, and the volume was recorded.

Body core temperature was measured using an ingestible temperature pill that was swallowed $5 \mathrm{~h}$ before the experiment (Mini Mitter Company, Inc. Bend, Oregon, U.S.A.). These data were recorded at 15-s intervals (Vitalsense Integrated Physiological Monitoring System, Mini Mitter Company, Inc. Bend, Oregon, USA). Heart rate was measured at 5-s intervals (model 810, Polar Electro Oy, Kempele, 10 Finland).

Participants ran on a treadmill (h/p/cosmos gmbh, Nussdorf-Traunstein, Germany) with speed individually adjusted to achieve the target work rate. To simulate air movement, three, 50-cm diameter fans (JS Humidifiers Plc., Littlehampton, U.K.) were arranged vertically to provide an even wind distribution at $2.0 \mathrm{~m} . \mathrm{s}^{-1}$.

Participants exercised in standardised running clothing (Quechua Novadry, Decathlon, France), cotton socks and running shoes without absorbent pads on the body. To collect sweat samples, pads were applied in the last 5 min of each work intensity only. Following 30 min of running at the first intensity, and again after 20 min at intensity two, the participant ceased exercise, removed their footwear and the skin was towel dried. At this time, infrared images of the foot surfaces were recorded to evaluate local and mean foot skin temperatures (Thermacam B2 and Thermacam Reporter Pro, FLIR Systems Ltd., West Malling, Kent, U.K.). Next, pads were taken out of their plastic storage bags and applied to the skin. Shoes were put on again and participants continued their run for the 5-min sweat collection phase. At the conclusion of this period, the sweat patches were removed and sealed in their plastic storage bags, the skin dried, and infrared images taken for temperature registration, after which the participant dressed without pads to continue the test.

Sweat samples were simultaneously collected from six foot sites from both feet: the 
1 plantar (surface areas shown are for a single foot: sole: $89 \mathrm{~cm}^{2}$ (SD 26)) and dorsal

2 (upper) surfaces $\left(285 \mathrm{~cm}^{2}\right.$ (SD 76)), the plantar surface of the toes $\left(53 \mathrm{~cm}^{2}\right.$ (SD 15)),

3 the plantar surface of heels $\left(42 \mathrm{~cm}^{2}\right.$ (SD 16)), and the medial (inside) $\left(84 \mathrm{~cm}^{2}\right.$ (SD

4 21)) and lateral (outside) ankle surfaces $\left(76 \mathrm{~cm}^{2}\right.$ (SD 19)). On average, these

5 patches covered $90-95 \%$ of the foot surface. Socks were pre-fitted with five

6 absorbent patches, with the location of each patch marked on each sock. However,

7 for the dorsal surface, the cotton sock itself was used as the absorbent. Latex socks

8 (Tribord Decathlon, Lille, France) were applied over the cotton socks to ensure the

9 pads were in intimate contact with the target skin surface, and to prevent evaporation

10 during the sweat measurement. Absorbent patches were placed on the lower leg to

11 avoid sweat from higher areas contaminating the foot patches.

12

Local sweat rates were derived from changes in pad masses, measured inside their plastic air-tight storage bags (Sartorius 1213MP, Sartorius AG, Gottingen, Germany; resolution $0.01 \mathrm{~g}$ ). Since the original mass of the dorsal section of sock on its own was unknown, it was dried for $24 \mathrm{~h}$, resealed inside its airtight bag and weighed to establish its dry, pre-test mass. Local sweat production was calculated as:

Sweat rate $=\left[\left(m_{w}-m_{d}\right) / S A\right] / t * 60 \quad\left(m g \cdot \mathrm{cm}^{-2} \cdot \mathrm{min}^{-1}\right)$

where:

$\mathrm{m}_{\mathrm{w}}=$ wet mass $(\mathrm{mg})$

$\mathrm{m}_{\mathrm{d}}=$ dry mass $(\mathrm{mg})$

$\mathrm{SA}=$ surface area of pad $\left(\mathrm{cm}^{2}\right)$

$\mathrm{t}=$ sample time $(\mathrm{s})$

$60=$ time correction constant $\left(\mathrm{s} \cdot \mathrm{min}^{-1}\right)$.

Whole-body (gross) sweat loss was calculated from body mass differences between the start and end of each trial, adjusted for fluid consumption.

\subsubsection{Data analysis:}

Data for males and females were analysed separately, and in comparison, using repeated-measures, one-way analyses of variance with and without Bonferroni corrections. Since the primary purpose of this paper is to describe sweating within 
1 the foot, data are presented as means with standard deviations (SD). Alpha was set

2 at the 0.05 level for all analyses.

4 2.2. Sweat-capsule study:

5 2.2.1. Participants:

6 Ten healthy and physically active adults (five males and five females: 24.5 y (SD

$7 \quad 2.2), 64.9 \mathrm{~kg}$ (SD 9.5), $173.7 \mathrm{~cm}$ (SD 10.2)) were sequentially exposed to passive

8 (rest: $50 \mathrm{~min}$ ) and semi-recumbent, one-legged, incremental cycling in a heated,

9 climate-controlled chamber $\left(36^{\circ} \mathrm{C}, 60 \%\right.$ relative humidity) while wearing a whole-

10 body perfusion suit provided with heated water $\left(40^{\circ} \mathrm{C}\right)$. These forcing functions were

11 designed to gradually induce hyperthermia and volitional fatigue, thus ensuring that

12 the sweating responses were measured across a broad range of thermal strain. No

13 participant suffered from hyperhidrosis or other sudomotor disorders. The Human

14 Research Ethics Committee (University of Wollongong) approved all methods, and participants provided written, informed consent prior to participation.

\subsubsection{Experimental methods:}

18 Participants wore running shorts and sports brassiere, but only one running shoe

19 (right foot). Each was asked to refrain from strenuous exercise and from alcohol and 20 tobacco consumption during the $12 \mathrm{~h}$ before a trial. Before entering the chamber, participants were instrumented (thermistors, sweat capsules) and dressed in the water-perfusion garment (Cool Tube-suit, Med-Eng, Ottawa, Canada).

During passive heating, participants rested for $50 \mathrm{~min}$ in a hot-humid environment, with the perfusion suit heating the skin using water from a regulated water bath (38litre water bath; Type VFP, Grant Instruments, U.K.), and provided at a flow of 0.3 L. $\min ^{-1}$ (Delta Wing pump, Med-Eng, Ottawa, Canada).

Incremental cycling was performed on an electronically braked ergometer (Lode use by two cyclists. Participants cycled in the semi-recumbent position with the right 
1 leg, completing approximately $50 \%$ of the external work. An assistant cycled in the

2 standard posture with the left leg. This technique allowed the left foot of the

3 participant to remain stationary for the analysis of local sweat secretion, whilst

4 facilitating extended-duration cycling without undue discomfort and premature

5 fatigue. Exercise commenced at a work rate of $50 \mathrm{~W}$ (15 min), which was followed by

$6 \quad 25-\mathrm{W}$ increments at 15-min intervals. On average, participants exercised for $68.2 \mathrm{~min}$

7 (SD 11.2) following the 50 min of passive heating. Exercise was terminated at

8 volitional fatigue or when core temperature exceeded $39.0^{\circ} \mathrm{C}$, with all participants

9 terminating at, or before a work rate of $175 \mathrm{~W}$.

Local sweat rates were measured using ventilated sweat capsules positioned at the forehead (reference site) and at eleven sites on the passive, nude, left foot (Figure 1B). Six larger capsules $\left(3.16 \mathrm{~cm}^{2}\right)$ were attached to the forehead, dorsal foot (two capsules) and the plantar surface (sole: three capsules). Six smaller sweat capsules $\left(1.40 \mathrm{~cm}^{2}\right)$ were attached to the big toe (dorsal and plantar surfaces), and to the medial (two capsules) and lateral (two capsules) aspects of the foot. This design permitted the pooling (averaging) of data within similar intra-segmental sites to describe sweating on six foot surfaces: the dorsal foot (centre and rear), dorsal toe, medial foot (front and rear), lateral foot (front and rear), the sole (front, centre, rear) and the plantar surface of the big toe.

Capsules were glued to the skin to prevent leakage and pressure-induced artefacts (Collodion U.S.P., Mavidon Medical Products, FL, USA). The pre-capsular airflow to each capsule was independently regulated at 0.3 L. min $^{-1}$ (small capsules) and 0.6 L. $\min ^{-1}$ (large capsules). The relative humidity of this air was maintained at $12 \%$ by passing room air over a saturated lithium chloride solution. Post-capsular humidity was measured using capacitance hygrometers (Clinical Engineering Solutions, NSW, Australia), with the inlet and exhaust air temperatures, and exhaust humidities sampled simultaneously at 1-s intervals from six channels (DAS1602, Keithley Instruments, Inc., Cleveland, OH, U.S.A.). These data were used to compute local sweat rates (Taylor et al., 1997). Hygrometer calibration, using saturated salt 
solutions, preceded experimentation.

This data acquisition system allowed localised sweat data to be recorded from only six sites simultaneously, though all 12 capsules were positioned during preparation. The remaining six capsules were continuously ventilated with room air, since this prevents sweat droplets from forming beneath each capsule. During passive heating, sweating from six foot sites was measured (plus forehead). During cycling, the sites of measurement were interchanged every $15 \mathrm{~min}$ (at each step change in work rate), with sweat capsules being connected to the sweat system in an alternating pattern. Since the air within both capsule ventilation systems had equilibrated with chamber air temperature before reaching the skin surface, there were no local thermal influences on sweating induced by these changes. In addition, data for the first 7.5 min of each sampling period were discarded. To minimise order effects associated with capsule rotation, two different measurement sequences were created (Figure 1B: trials $A$ and $B$ ). This ensured that the sites investigated at the start of each trial were studied in a balanced order across participants. Participants each completed their single trial in a different sequence. Five minutes prior to each work rate increase, the sites of sweat measurement were manually changed ( $2 \mathrm{~min}$ ) so that the other sites were now connected to the sweat system. This rotation pattern continued until the trial ended, and permitted the collection of data from the middle 2 min of each work load that was not influenced by capsule changes.

Body core temperature (insulated auditory canal) and skin temperatures were continuously measured using thermistors (Edale instruments Ltd., Cambridge, U.K.). Auditory canal temperature was chosen as the representative core temperature due to the minimal impact of air temperature on this index under the current experimental conditions. Skin temperatures were measured at the forehead, chest, scapula, upper arm, forearm, dorsal hand, thigh and calf, and an area-weighted summation of these temperatures was used to compute mean skin temperature (ISO 9886:1992). In addition, local skin temperatures of the dorsal, medial, lateral and plantar (sole) aspects of the foot, and the medial aspect of the big toe were recorded to evaluate 
1 local thermal influences on sweat secretion. All temperatures were recorded at 5-s

2 intervals using a portable data logger (1206 Series Squirrel, Grant Instruments Pty

3 Ltd., Cambridge, U.K.). Thermistors were calibrated against a reference

4 thermometer in a stirred water bath (Dobros total immersion, Dobbie Instruments,

5 Sydney, Australia). Heart rate was measured at 15-s intervals (Vantage NV Sports

6 Tester, Polar Electro Oy, Kempele, Finland).

7

8 2.2.3. Data analysis:

9 Intra-segmental differences in sweating were evaluated from the 2-min periods in the

10 middle of each work rate, immediately before changing sites of sweat measurement.

11 Data were analysed using one-way analyses of variance and Tukey's HSD post hoc

12 tests, with no attempt to differentiate between genders. Alpha was similarly set at the

130.05 level for all analyses, with data presented as means with standard deviations

14 (SD).

\section{Results}

\subsection{Sweat-patch study:}

18 During the 5-min sweat collection phase of the low and high exercise intensities,

19 heart rates averaged 134 beats $\min ^{-1}$ (standard deviation [SD] = 4) and 156

20 beats. $\min ^{-1}$ (SD 4) respectively. The corresponding core temperatures were $37.8^{\circ} \mathrm{C}$

21 (SD 0.3) and $38.1^{\circ} \mathrm{C}$ (SD 0.3). While these data differed significantly between the two exercise intensities $(P<0.01)$, gender differences were only apparent for the baseline core temperature (lower for males) and the absolute work rates necessary

24 to elicit the target exercise intensities (both $P<0.01$ ). That is, females achieved the same target heart rate with less power produced and thus generated less heat. There were no skin temperature differences between right and left feet, nor were there gender-related differences in the local skin temperatures. The former permitted pooling of data from both feet, within participants.

The males presented evidence for a non-uniform distribution of sweating (Figure 2), and this variability within the foot was significantly greater than that observed in the 
1 females $(P<0.01$; Figure 3$)$. Males secreted significantly more sweat in all zones than

2 females (about 2.2 times more). The highest local sweat rate was observed from the

3 medial surface of the ankles in males ( $P<0.01$ compared to all other zones) and

4 females $(P<0.05$ for all zones except heel), followed by the dorsal foot in the males.

$5 \quad(P<0.05$ compared to sole, toes and heel) with the plantar areas having the lowest

6 sweat rates. In the females, none of the other zones were significantly different from

7 each other.

\section{INSERT FIGURES 2 AND 3 ABOUT HERE}

10

11

Whilst the local skin temperatures of the foot differed following both exercise intensities $(P<0.01)$, there was no evidence of a correlation between the local skin temperatures and local sweat rates during either exercise intensity $(P<0.01)$.

\subsection{Sweat-capsule study:}

Following passive heating, mean skin temperature increased from $33.5^{\circ} \mathrm{C}$ to $36.6^{\circ} \mathrm{C}$, while the core temperature rose from $36.8^{\circ} \mathrm{C}$ to $37.3^{\circ} \mathrm{C}$, and the final resting heart rate was 87 beats. $\mathrm{min}^{-1}$. During this stage, a progressive elevation in sweat secretion was observed from all foot surfaces, with a non-uniform distribution (Figure 4), as observed in the males of the sweat-patch study. Indeed, the plantar (sole and toe) surfaces of the foot (for location see Figure 1) possessed the lowest sweat rates $(P<0.01)$, while the dorsal surface of the first toe produced the most sweat $(P<0.01)$. However, significant differences in sweating were not observed among sites located within the same part of the foot $(P>0.05)$. Therefore, data from within these locations were pooled to furnish six intra-segmental sweat locations (Figure 4). 
6 Participants terminated incremental exercise with a mean core temperature of $38.9^{\circ} \mathrm{C}$ (SD 0.1) and heart rates averaging $170 \mathrm{~b} \cdot \mathrm{min}^{-1}$ (SD 5), thereby ensuring that sweating responses were indeed obtained across a wide range of physiological strain. Under these conditions, forehead secretion averaged $2.76 \mathrm{mg} \cdot \mathrm{cm}^{-2} \cdot \mathrm{min}^{-1}$ (SD 0.36 ) across the exercise duration. This was $>50 \%$ more than that recorded from the most prolific secretion sites of the foot (dorsal surface of the first toe). Sweating within each foot region (i.e. sole, dorsal, medial and lateral surfaces) did not differ significantly during exercise $(P>0.05)$, thus permitting data pooling and the provision of six intra-segmental sites from the original eleven sites investigated (Figure 1).

As with passive heating, each foot site responded to the exercise with increases in sweating $(P<0.05)$ concordant with changes in exercise intensity (Figure 5). These responses accentuated differences observed during passive heating, and within the last exercise stage, local peak sweat rates averaged: $14.4 \mathrm{~mL} \cdot \mathrm{h}^{-1}$ (central dorsal surface), $14.2 \mathrm{~mL} . \mathrm{h}^{-1}$ (dorsal toes), $5.4 \mathrm{~mL} . \mathrm{h}^{-1}$ (medial surface), $4.5 \mathrm{~mL} . \mathrm{h}^{-1}$ (lateral surface), $2.9 \mathrm{~mL} . \mathrm{h}^{-1}$ (plantar surface (sole)), and $1.1 \mathrm{~mL} \cdot \mathrm{h}^{-1}$ (plantar toe). Significant main effects for measurement sites were present for comparisons between the plantar toe (lowest) and each of the other locations $(P<0.05)$, except for the sole $(P=0.076)$. Sweating from the plantar surface differed significantly from all sites $(P<0.05)$, except for the medial $(P=0.065)$ and lateral aspects of the foot $(P>0.05)$. In addition, dorsal foot sweat rates, which had previously been described to be the highest within the foot (Taylor et al., 2006), were significantly greater than measured from the lateral foot surface $(P<0.05)$, with dorsal toe secretion exceeding that from the medial foot $(P<0.05)$. Finally, significant site-by-time interactions were evident (Figure 5) for the comparisons between the plantar toe and each of the other foot sites $(P<0.05)$, except the sole $(P=0.068)$. 
To derive an integrated view of these intra-segmental sweating differences, data were averaged across the entire exercise phase (Figure 6). In general, these data showed the highest sweat rates appeared across the dorsal foot surface (including the big toe), with the medial and lateral aspects displaying intermediate secretion rates, and the plantar regions (sole and big toe) being the least responsive to these thermal and exercise stresses.

INSERT FIGURE 6 ABOUT HERE

When considered across the eleven measurement sites within the foot, across both genders during rest and exercise, and across core temperatures ranging from 36.8$38.9^{\circ} \mathrm{C}$, the average discharged sweat from one foot was $0.76 \mathrm{mg} \cdot \mathrm{cm}^{-2} \cdot \mathrm{min}^{-1}(27.6$ $\left.\mathrm{mL} \cdot \mathrm{h}^{-1}\right)$. For applied purposes, but also on the basis of the integrated sweat responses, one could sub-divide the foot into four zones, which can be assigned the following fractional area weightings and shapes: plantar surface (40\%: rectangular), dorsal surface (25\%: rectangular), and the medial (15\%: wedge) and lateral surfaces (15\%: wedge). It was further assumed that the dorsal and plantar toe surfaces each represented $5 \%$ of the foot surface. From these assumptions, the following local sweat rates from a single foot were computed using data derived during exercise: $9.6 \mathrm{~mL} . \mathrm{h}^{-1}$ (central dorsal surface), $3.9 \mathrm{~mL} . \mathrm{h}^{-1}$ (medial surface) $3.5 \mathrm{~mL} . \mathrm{h}^{-1}$ (lateral surface), $7.5 \mathrm{~mL} . \mathrm{h}^{-1}$ (plantar surface (sole)), $2.2 \mathrm{~mL} . \mathrm{h}^{-1}$ (dorsal toes), and $0.8 \mathrm{~mL} . \mathrm{h}^{-1}$ (plantar toes). Therefore, approximately $70 \%$ of the total sweat secreted from the foot is likely to appear on its upper surfaces (including medial and lateral sites). There were seven capsules positioned at these sites, and they revealed an average secretion rate of $0.90 \mathrm{mg} . \mathrm{cm}^{-2} \cdot \mathrm{min}^{-1}$ during exercise. For the plantar surfaces (three 
1 capsules), the corresponding mean sweat flow was $0.47 \mathrm{mg} \cdot \mathrm{cm}^{-2} \cdot \mathrm{min}^{-1}$.

\section{4. Discussion}

4 The hands and feet possess very high, area-specific heat conservation and

5 dissipation capacities (Taylor et al., 2009), and this paper has established that, while

6 the plantar surface is absolutely thermo-responsive, the dorsum (upper part) of the

7 foot is capable of producing $65-70 \%$ of the sweat discharged from each foot (Taylor

8 et al., 2006; Fogarty et al., 2009). These last characteristics were reinforced by the current data, rendering these as facts confirmed by separate experiments using different techniques.

To these attributes, we can now add a number of new findings. Firstly, when measured with sweat capsules, sweating from bare feet progressively increases when heat strain increases (Figure 5). However when measured inside shoes, sweat rate levels off (Figure $2 \& 3$ ). This difference may be caused by the measurement technique, as introduced earlier. In the capsule system, skin is kept dry and sweating increases with core temperature. In the absorbent method, measurements took place inside the actual shoe. Though the patches were applied only briefly ( $5 \mathrm{~min})$, the feet were enclosed in the shoe for the whole test. Hence, moisture build-up in socks and shoes may have induced slight hidromeiosis (skin swelling due to hydration, closing sweat ducts), causing sweating to level off. In this case, the sweat absorbent technique may produce the more realistic results for the feet, which are usually enclosed. Secondly, the data obtained wearing shoes showed a lower variation in sweat rate than was observed over the nude foot within the sweat capsule trials (Figure $2 \& 6$ ). However, this variation seems to be less evident in females (Figure $2 \& 3$ ), and variation was also minimal on the sole in both studies. Thirdly, from the running experiments, it was observed that the male foot secreted more than twice the sweat produced by the feet of women for the same relative workload (same heart rate). This was, in part, caused by the males having a $45 \%$ higher metabolic heat production at this same heart rate. Fourthly, if one compares the capsule data to the absorbent data, the patterns of sweat distribution are very 
1 similar. Of the zones measured in both experiments, the dorsal foot sweats most and

2 the plantar toe and the sole the least. This is the case for both the passive and the exercise conditions. Finally, across both studies, the measured male sweat rates (for zones measured in all tests) were in very similar ranges: rest plus heat (hot skin) gives a range of $0.23-0.50 \mathrm{mg} \cdot \mathrm{cm}^{-2} \cdot \mathrm{min}^{-1}$; running with a core temperature of approximately $38^{\circ} \mathrm{C}$ gives $0.30-0.50 \mathrm{mg} \cdot \mathrm{cm}^{-2} \cdot \mathrm{min}^{-1}$; and cycling to exhaustion and a core temperature of $38.9^{\circ} \mathrm{C}$ produced an average secretion of $0.41-1.20$

$8 \mathrm{mg} \cdot \mathrm{cm}^{-2} \cdot \mathrm{min}^{-1}$.

When comparing the present data, in terms of whole-foot sweat generation, with data from literature, there is good agreement. Capsule data estimate a sweat loss of $27.6 \mathrm{~g} \cdot \mathrm{h}^{-1}$ per foot. The absorption data indicate this to be $23 \mathrm{~g} \cdot \mathrm{h}^{-1}$ per foot for the low activity and $32 \mathrm{~g}^{-1} \mathrm{~h}^{-1}$ for the higher activity. These latter data compare favourably with data reported by Fogarty et al. (2009: 15- $29 \mathrm{~g} \cdot \mathrm{h}^{-1}$ ) for low- and high-intensity uphill walking carrying a back pack.

A principal limitation of quantifying discharged sweat from active and clothed surfaces, specifically the palmar/plantar aspects of the hands and feet, is the interference of physical activity on these measurements. In the current investigation, two novel solutions were implemented, making it possible for sweat to be measured in 32 participants, from eleven sites across the foot surface, and even from within shoes during running. Indeed, these observations enable a clearer understanding of the entire range of sweating occurring in resting and passively heated individuals, through to people undertaking two steady-state running intensities, and finally to others involved in incremental cycling to profound, but regulated hyperthermia. Given that sweat capsule techniques tend to over-estimate sweating in clothed people, and sweat-patch methods may artificially suppress sweating, then one may reasonably assume that actual foot sweat rates may be located between these two data sets. The fact that the observed sweat rate ranges overlap strengthens these data.

31 These observations can be used in various ways. Apart from the pure academic 
1 interest in gender differences and in sweat generation, these data facilitate a number

2 of practical applications. The first is their use in footwear design. On various

3 occasions the authors were asked for foot sweat data by clothing and footwear

4 designers to help them consider required moisture absorption rates and required

5 moisture transfer rates for footwear. The current results indicate that a greater need

6 exists for the removal of sweat from the dorsal surface than from the plantar surface,

7 although sweat rates on either location were not high. On the other hand,

8 permeability of the sole of a shoe will be much lower than for the top. In this context,

9 it is worth noting that typical permeabilities of shoes for moisture are far less than the

10 sweat productions currently observed. Moisture transfer in footwear is often

11 problematic, especially when water repellence or waterproofing is desired. Fabrics

12 are treated to achieve this objective, or semi-permeable membranes are included

13 within footwear. These typically reduce moisture permeation, and thus moisture

14 absorption capacity becomes more important. For example, moisture permeability of nappa leather, measured on a control dish system (ISO 14268, in ideal conditions) amounts to around $40 \mathrm{~g} \cdot \mathrm{m}^{2} \cdot \mathrm{h}^{-1}$. When coated with pigments, this drops towards 27 g. $\mathrm{m}^{2} \cdot \mathrm{h}^{-1}$, and with a not uncommon microporous waterproofing (PU) to $10 \mathrm{~g} \cdot \mathrm{m}^{2} \cdot \mathrm{h}^{-1}$ (Jankauskaite et al., 2004). As the top surface of a shoe is a lot lower than $1 \mathrm{~m}^{2}$ (estimate between 0.03-0.06 $\mathrm{m}^{2}$ ), and the vapour pressure gradients across the material are mostly less than that in the standard test, where desiccant is used on one side, it may be clear that the actual vapour transfer possible through the shoe will be far below the moisture generated during exercise, as currently observed (23$\left.32 \mathrm{~g} \cdot \mathrm{h}^{-1}\right)$. This leaves three options. The first two are associated with increasing moisture loss: changing the shoe material (e.g. air-permeable textiles) or increasing shoe ventilation (Satsumoto et al., 2011). Where shoes can be made more open, the presented data allow estimates of the amount of permeation or ventilation required in the footwear to remove most sweat (Ueda et al., 2006). The third option accepts that moisture will accumulate within the shoe, but focuses upon buffering of build up of moisture within the socks (Kuklane, $2000^{\mathrm{a}}$ ), or the insole. Felt insoles for example allow substantial moisture absorption before affecting the wearers comfort or the shoe insulation. Such use would require a good drying regime between uses to avoid 
excessive moisture accumulation. This may be critical in cold weather applications in

2 long term wear situations as in the military.

3

4 A second application of these data is the design of sweating, thermal manikins or

5 specialised sweating feet for footwear testing (Babic et al., 2008). In the past, these

6 had uniform sweat rates over the whole body, but with data like those presented

7 here becoming available, more physiologically relevant designs are possible,

8 providing more realistic simulations. Finally, these data can be used by those

9 modelling thermoregulation (e.g. Covill et al., 2011), allowing these researchers to

10 differentiate sweating for different body parts.

\section{Conclusion}

13 Two general conclusions may be derived from this series of experiments on the 14 sweating foot. Firstly, the feet are not sites of prolific sweat production during rest, but they produce moderate flows from the dorsal surface during exercise, which go beyond the typical vapour permeation capability of shoe materials. Secondly, the feet may be considered to have at least two general sweat distribution patterns during exercise in the heat, with low secretion rates from the sole and the lateral foot, and with significantly greater sweating from the dorsal surfaces. 


\section{References}

2 Allen, J.A., Armstrong, J.E., and Roddie, I.C. (1974), "The regional distribution of emotional sweating in man", J. Physiol., Vol. 235, pp.749-759.

Allen, J.A., Robinson, P.H., and Roddie, I.C. (1978), "Thermal sweating from the palms and soles", J. Physiol., Vol. 285, pp. 35P-36P.

Babic, M., Lenarcic, J., Zlajpah, L., Taylor, N.A.S., and Mekjavic, I.B. (2008), "A device for simulating the thermoregulatory responses of the foot: estimation of footwear insulation and evaporative resistance", J. Mech. Eng., Vol. 54(9), pp. 622-638.

Collins, K.J., and Weiner, J.S. (1962), "Observations on arm-bag suppression of sweating and its relationship to thermal sweat-gland 'fatigue'”, J. Physiol., Vol. 161 , pp. 538-556.

Covill, D., Guan, Z.W., Bailey, M., Raval, H. (2011) "Development of thermal models of footwear using finite element analysis." Proceedings of the Institution of Mechanical Engineers, Part H: Journal of Engineering in Medicine. DOI 10.1243/09544119JEIM860

Fogarty, A.L., Barlett, B., Ventenat, V., and Havenith, G. (2009), "Regional foot sweat rates during a 65-minute uphill walk with a backpack", In: Mekjavic, I.B., Kounalakis, S.N., and Taylor, N.A.S. (Editors), Environmental Ergonomics XII. Biomed d.o.o., Ljubljana, Slovenia. ISBN: 978-961-90545-2-9. pp. 277-228.

Havenith, G. (2002) "Interaction of clothing and thermoregulation”, Exogenous Dermatology, 1 (5), pp. 221-230.

Havenith, G., Fogarty, A., Bartlett, R., Smith, C.J., and Ventenat, V. (2008 ${ }^{a}$ ), "Male and female upper body sweat distribution during running measured with technical absorbents", Eur. J. Appl. Physiol., Vol. 104, pp. 245-255.

Havenith, G., Smith, C., Fukazawa, T. $\left(2008^{\mathrm{b}}\right)$ "The Skin Interface - Meeting Point of Physiology and Clothing Science", Journal of Fiber Bioengineering and Informatics JFBI Vol.1 No. 22008 93-98.

Hertzman, A.B., Randall, W.C., Peiss, C.N., and Seckendorf, R. (1952), "Regional rates of evaporation from the skin at various environmental temperatures", J. Appl. Physiol., Vol. 5, pp. 153-161. 
1 ISO 9886. (1992), "Evaluation of thermal strain by physiological measurements", International Standard Organisation, Geneva.

Jankauskaitè, V., Gulbinienè, A., Mickus, K.V., (2004) "Effect of Leather Finishing Technology on Water Vapour Transmission. Part II. Water Vapour Transfer through Microporous Film Laminated Leather", Materials Science (Medžiagotyra) 10 (3) pp. 249 - 254.

Kuklane, K., Holmér, I., and Giesbrecht, G. (2000a) "One week sweating simulation test with a thermal foot model", Proceedings of the Third International Meeting on Thermal Manikin Testing, 3IMM, at the National Institute for Working Life, October 12-13, 1999 pp104-113; Eds. Nilsson, Håkan and Holmér, Ingvar.

Kuklane, K., Holmer, I. and Havenith G., (2000b) "Validation of a Model for Prediction of Skin Temperatures in Footwear"; J. Physiol. Anthrop. Appl. Human Sci, Vol. 19, No. 1 pp.29-34.

Kuno, Y. (1956), "Human perspiration", C.C. Thomas, Springfield, Illinois. Machado-Moreira, C.A., and Taylor, N.A.S. (2011a), "Psychological sweating from glabrous and non-glabrous skin surfaces under thermoneutral conditions', Psychophysiol. DOI: 10.1111/j.1469-8986.2011.01309.x [Epub ahead of print] Machado-Moreira, C.A., and Taylor, N.A.S. (2011b), "Sudomotor responses from glabrous and non-glabrous skin during cognitive and painful stimulations following passive heating", Acta Physiol. DOI: 10.1111/j.17481716.2011.02362.x. [Epub ahead of print].

Mekjavic, I.B., Lenart, B., Vrhovec, M., Tomsic, M., Bartels, V., Umbach, K.H., Kakitsuba, N., Taylor, N.A.S., and Oakley, H. (2005), "Static and dynamic evaluation of biophysical properties of footwear": The Jozef Stefan Institute sweating thermal foot manikin system. Proceedings of the Eleventh International Conference on Environmental Ergonomics. May 22 ${ }^{\text {nd }}-26^{\text {th }}, 2005$. Ystad, Sweden. ISBN: 91-631-7062-0, pp. 290-292.

Satsumoto., Y., Takeuchi, M., and Havenith., G. (2011) "the effect of size factor of leather shoes on ventilation rate in shoes" The Fourth International Conference on Human-Environment System ICHES-2011, Sapporo, Japan, 3- 
6 Oct., 2011; Ed. Shintaro Yokoyama.

Smith, C., Ventenat, V., and Havenith, G. (2007), "Regional sweat rates of the arms and hands in male squash players", In: Mekjavic, I.B., Kounalakis, S.N., and Taylor, N.A.S. (Editors), Environmental Ergonomics XII. Biomed d.o.o., Ljubljana, Slovenia. ISBN: 978-961-90545-1-2, pp. 285-288.

Smith, C., and Havenith, G. (2011) "Body mapping of sweating patterns in male athletes in mild exercise-induced hyperthermia" Eur. J. Appl. Physiol, Vol:111(7) pp 1391-1404

Taylor, N.A.S., Caldwell, J.N., and Mekjavic, I.B. (2006), "The sweating foot: local differences in sweat secretion during exercise-induced hyperthermia", Aviat. Space \& Environ. Med., Vol. 77, pp. 1020-1027.

Taylor, N.A.S., and Machado-Moreira, C.A. (2011), "Regional variations in sweat gland density, insensible and thermal perspiration, and the electrolyte composition of sweat: physiologists, modellers, engineers, lend us your ears", In: Kounalakis, S.N., and Koskolou, M. (Editors). Proceedings of the Fourteenth International Conference on Environmental Ergonomics. ISBN: 978-960-489-272-3, pp. 136-139.

Taylor, N.A.S., Machado-Moreira, C.A., van den Heuvel, A.M.J., Caldwell, J.N., Taylor, E.A., and Tipton, M.J. (2009), "The roles of hands and feet in temperature regulation in hot and cold environments", Proceedings of the Thirteenth International Conference on Environmental Ergonomics. ISBN: 978-1-74128-178-1, pp. 405-409.

Taylor, N.A.S., Patterson, M.J., Cotter, J.D., and Macfarlane, D.J. (1997), "Effects of artificially-induced anaemia on sudomotor and cutaneous blood flow responses to heat stress", Eur. J. Appl. Physiol., Vol. 76, pp. 380-386.

Ueda, H., Inoue, Y., Matsudaira, M., Araki, T. and Havenith, G., (2006) "Regional microclimate humidity of clothing during light work as a result of the interaction between local sweat production and ventilation", Int. J. Cloth. Sci. Tech., Vol. 18(4), pp 225-234.

Wurster, R.D., Hassler, C.R., McCook, R.D., and Randall, W.C. (1969), "Reversal in patterns of sweat recruitment", J. Appl. Physiol., Vol. 26,pp. 89-94. 


\section{Figure captions}

Figure 1A: Location of sweat absorbent patches on the foot. 1B: Ventilated sweat capsule positions on the foot. Site codes: 1 : Dorsal foot 1; 2 : Dorsal foot 2; 3 : Lateral foot 1 (anterior); 4: Lateral foot 2 (posterior); 5: Dorsal toe; 6: Plantar toe; 7: Medial foot 1 (anterior); 8: Medial foot 2 (posterior); 9: Sole 1; 10: Sole 2 (centre); 11: Sole 3; 12: forehead. Two measurement sequences (trials $A$ [sites 2, 4, 5, 7, 10] and $B$ [sites $1,3,6,8,9,11])$ were used to ensure that measurement sites were investigated in a balanced order across participants. The forehead was used as a reference site.

Figure 2: Local sweating responses within the feet of males during treadmill running at two speeds in a climate-controlled room $\left(25^{\circ} \mathrm{C}\right.$ and $45 \%$ relative humidity). Data are means with standard deviations obtained using absorbent patches, and arranged in descending order as determined during low-intensity exercise. Statistical differences are described within the text.

Figure 3: Local sweating responses within the feet of females during treadmill running at two speeds in a climate-controlled room $\left(25^{\circ} \mathrm{C}\right.$ and $45 \%$ relative humidity). Data are means with standard deviations obtained using absorbent patches, and arranged in descending order as determined during low-intensity exercise. Statistical differences are described within the text.

Figure 4: Thermal sweating from five foot sites in resting, passively heated participants (Figure 1). These data are 2-min averages obtained at the end of $50 \mathrm{~min}$ of heating $\left(36^{\circ} \mathrm{C}, 60 \%\right.$ relative humidity, water-perfusion suit: $\left.40^{\circ} \mathrm{C}\right)$. Data are means with standard deviations collected using ventilated sweat capsules. ${ }^{*}=$ significantly different from the dorsal toe $(P<0.05)$.

Figure 5: Dynamic sweating responses of six foot sites (Figure 1) during incremental, one-legged cycling in the heat, following 50 min of passive heating 
$1 \quad\left(36^{\circ} \mathrm{C}, 60 \%\right.$ relative humidity, water-perfusion suit: $\left.40^{\circ} \mathrm{C}\right)$. For clarity, only means are 2 provided. Only five participants remained exercising at $150 \mathrm{~W}$, and data at $175 \mathrm{~W}$ $3(N=1)$ have been eliminated due to the high participant drop-out at, or before this 4 work rate. Statistical differences are described within the text. 5

6 Figure 6: Sweat secretion rates from six foot sites (Figure 1) averaged across 7 incremental, one-legged cycling in the heat (68.2 min (SD 11.2)), following 50 min of 8 passive heating $\left(36^{\circ} \mathrm{C}, 60 \%\right.$ relative humidity, water-perfusion suit: $\left.40^{\circ} \mathrm{C}\right)$. Data are 9 means with standard deviations collected using ventilated sweat capsules. * 10 significantly different from the dorsal toe $(P<0.05)$; $\dagger=$ significantly different from the 11 dorsal foot $(P<0.05)$. 
1 Figure 1
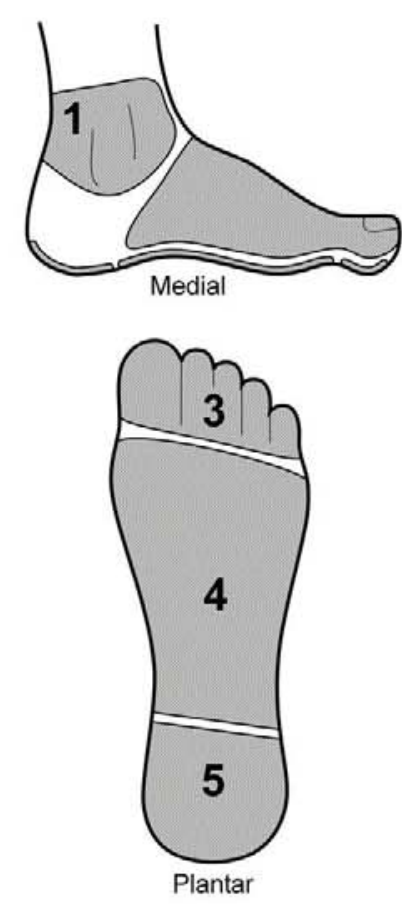

a
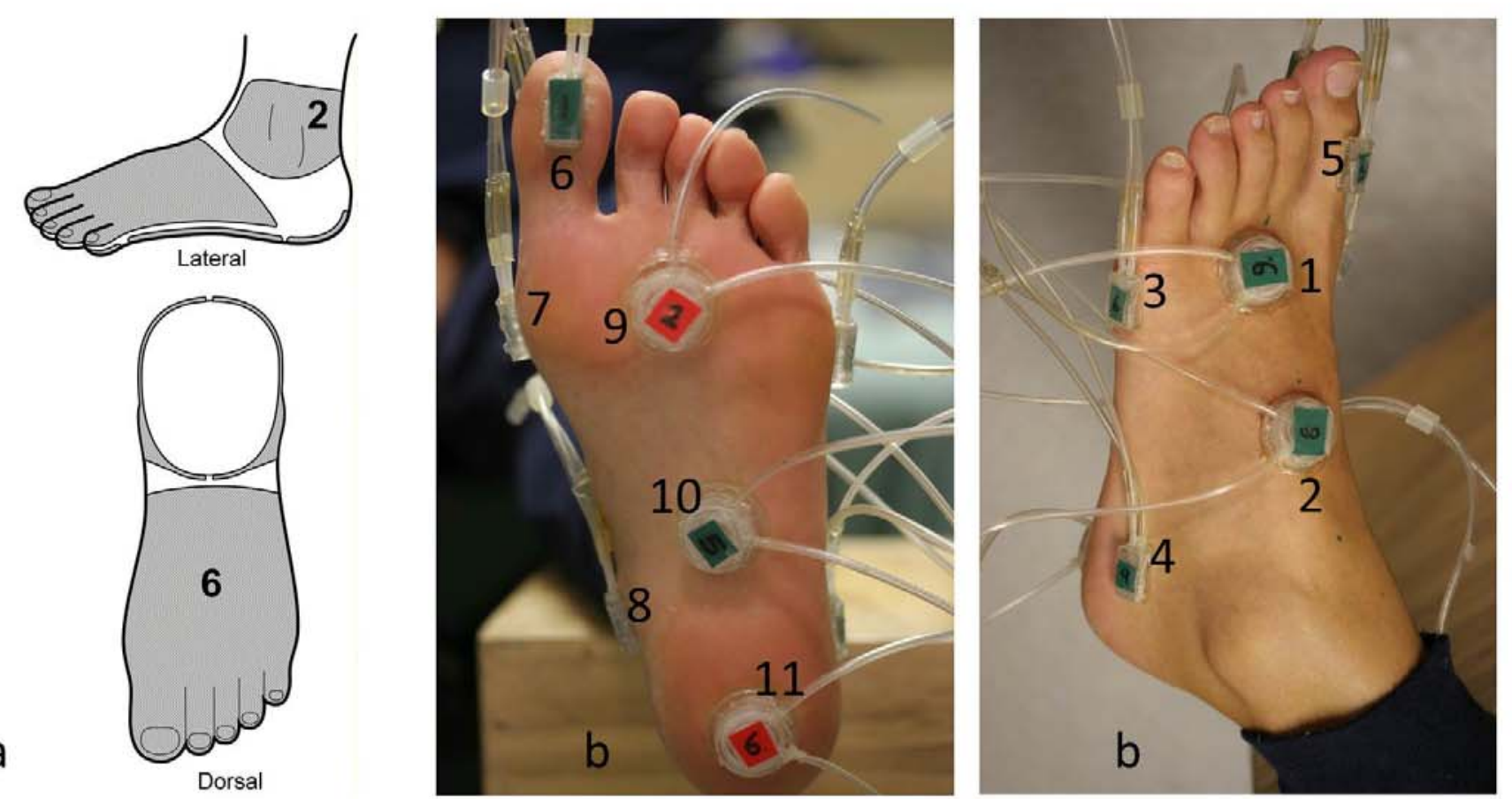

Page 24 
Figure 2:

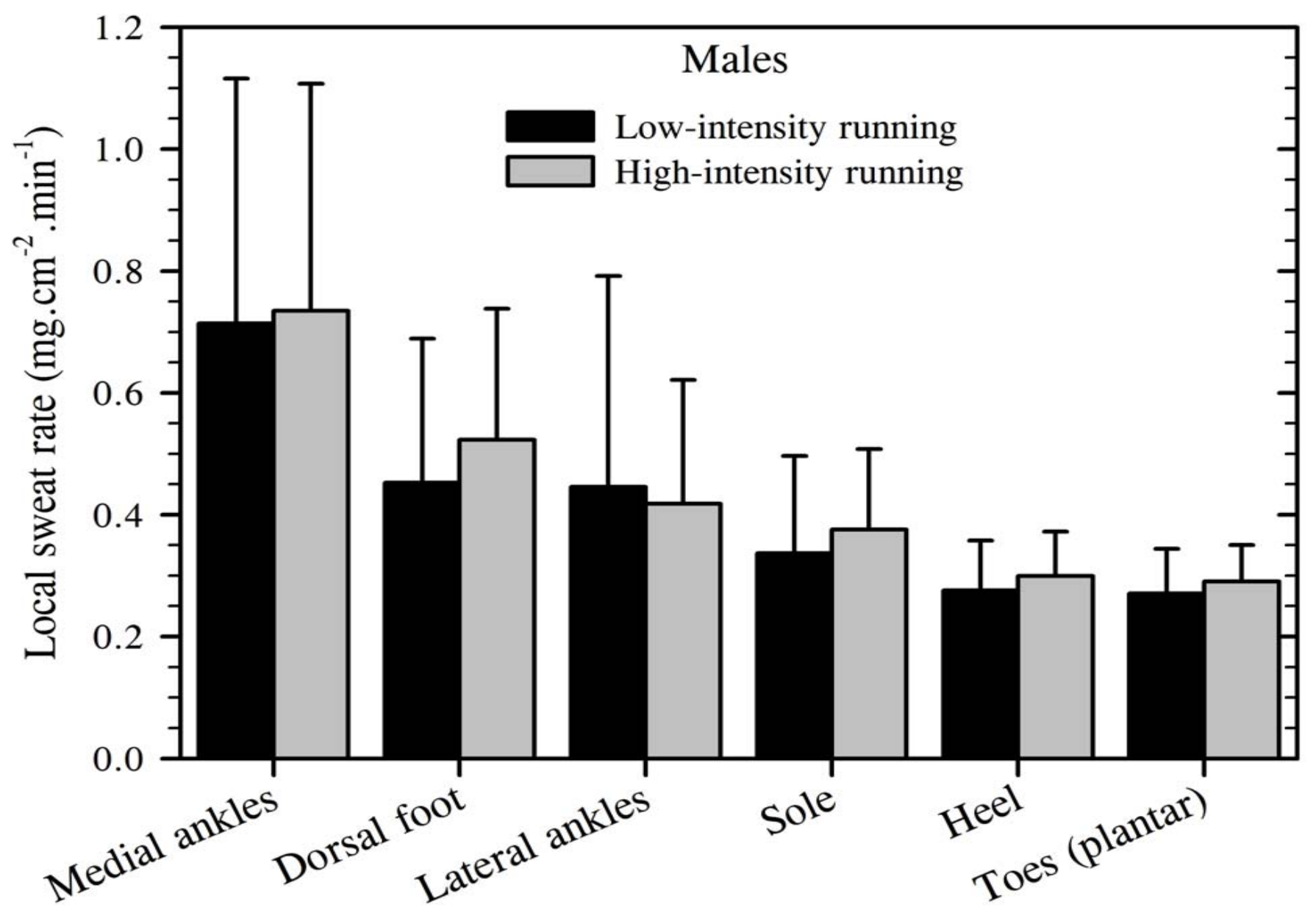


Figure 3:

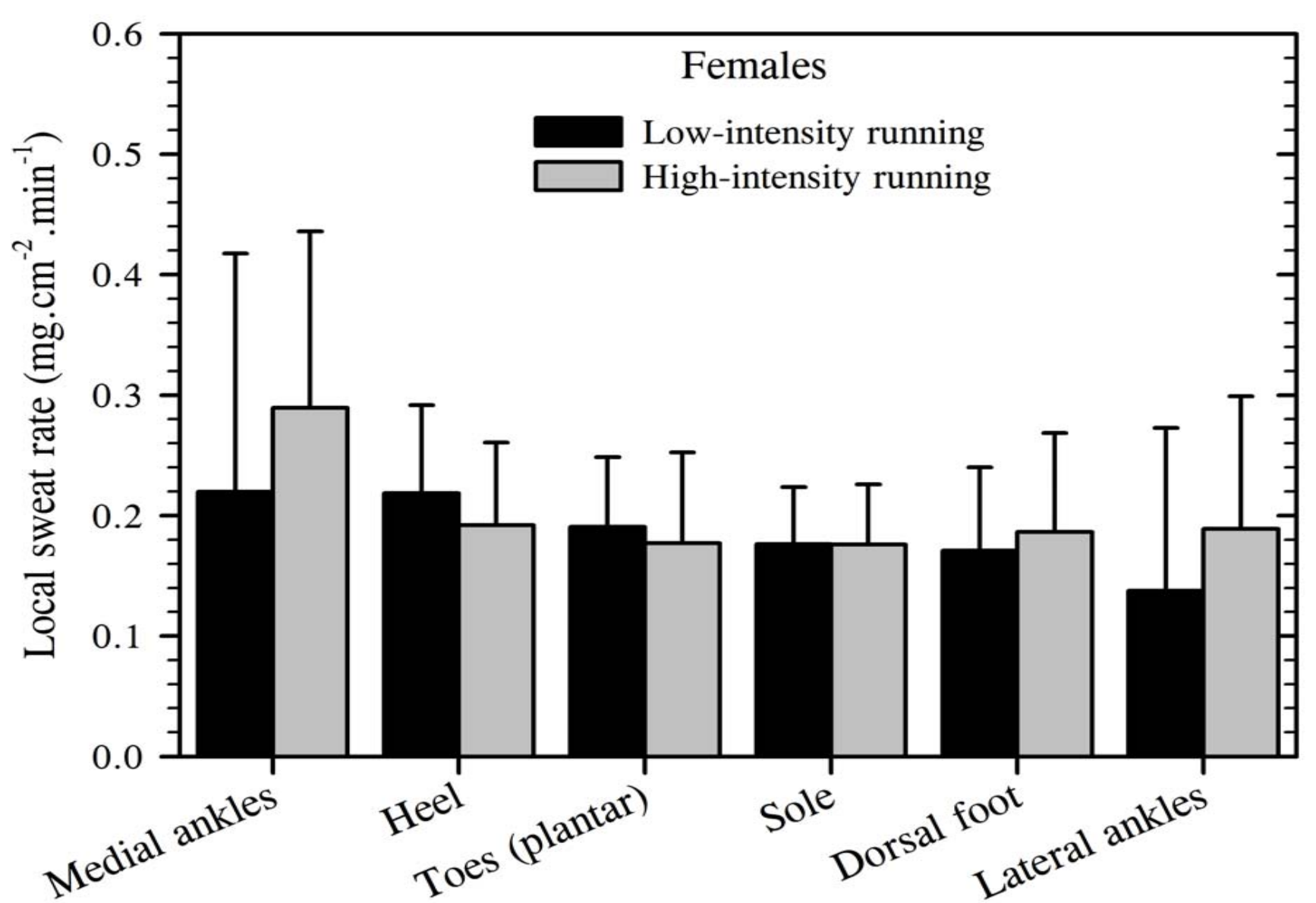

Page 26 
Figure 4:

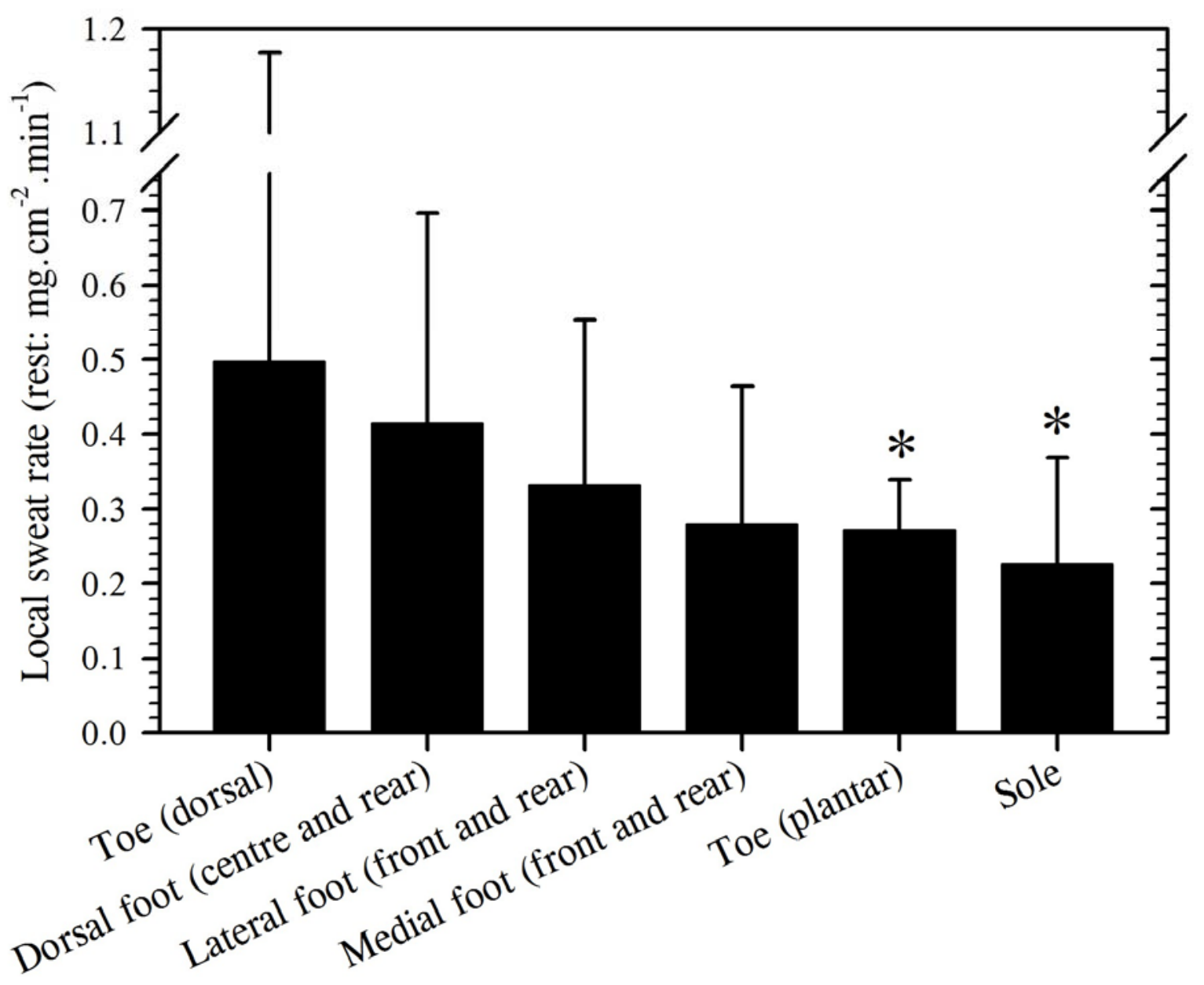

Page 27 
Figure 5:

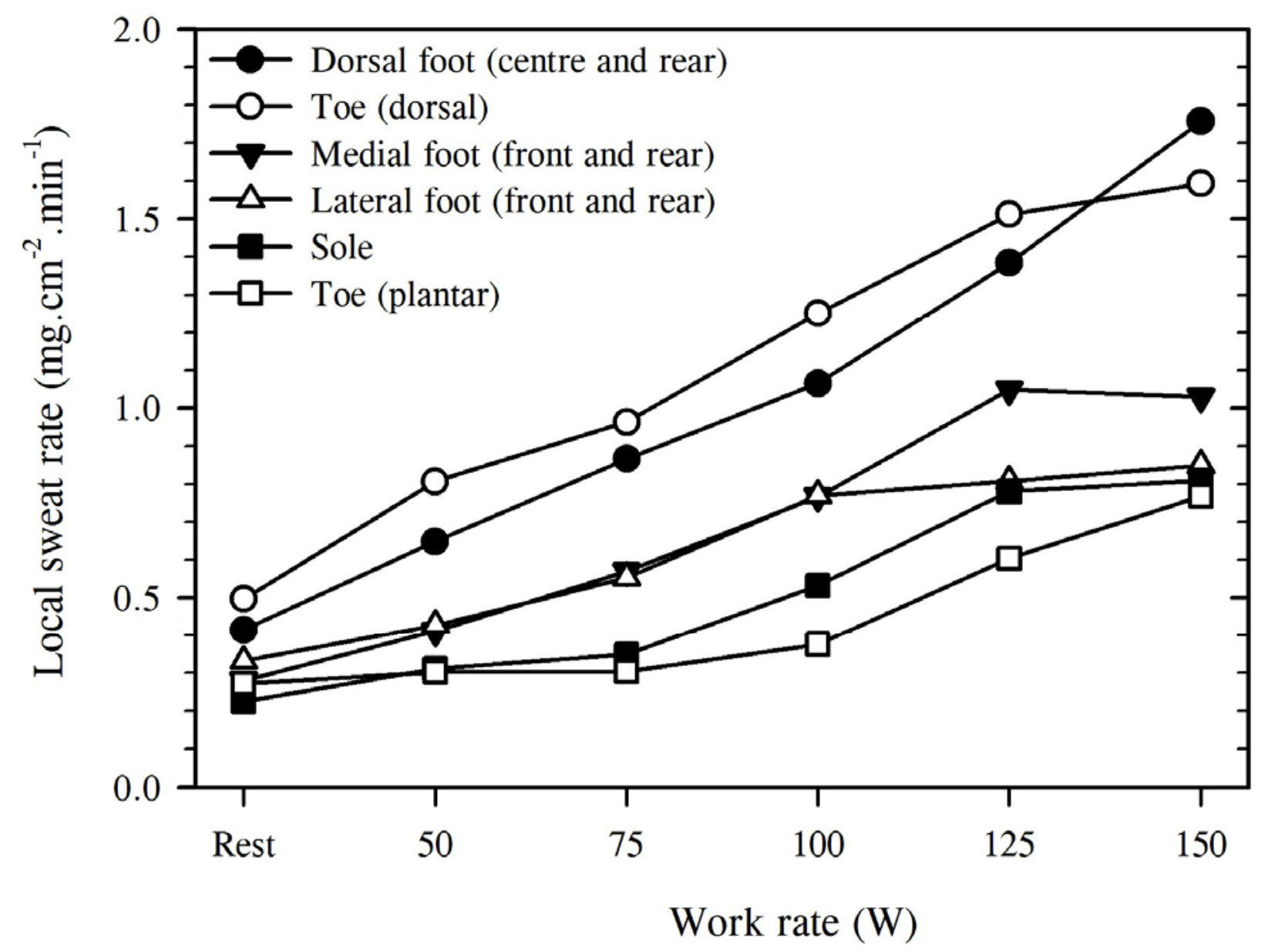

Page 28 

Foot sweating

1

Page 30 